\title{
ANALISIS PERTANYAAN GURU DAN SISWA DALAM PROSES PEMBELAJARAN BAHASA INDONESIA DI KELAS VII SMP NEGERI 4 KOTA BENGKULU
}

\author{
Dini Faizah, Padi Utomo, dan M. Arifin \\ Program Studi Pendidikan Bahasa Indonesia \\ Jurusan Pendidikan Bahasa dan Seni \\ FKIP Universitas Bengkulu \\ dinifaiz13@gmail.com
}

\begin{abstract}
Abstrak
Penelitian ini bertujuan untuk mendeskripsikan jenjang dan macam-macam pertanyaan yang diajukan oleh guru dan siswa dalam proses pembelajaran Bahasa Indonesia kelas VII-1, VII-3, dan VII-4 SMP Negeri 4 Kota Bengkulu tahun ajaran 2017/2018. Metode dalam penelitian ini adalah metode deskriptif kualitatif. Hasil analisis kemunculan pertanyaan yang diajukan oleh guru di kelas VII-1, VII-3, dan VII-4 dalam delapan kali pertemuan sebanyak enam puluh dua pertanyaan, kemudian pertanyaan sering muncul pada jenjang C-2 (memahami) dan macam pertanyaan yang diajuakan menurut cara adalah pertanyaan menggali. Pertanyaan yang diajukan oleh siswa adalah sebanyak tujuh pertanyaan, kemudian pertanyaan sering muncul pada jenjang C-2 (memahami) dan macam pertanyaan yang diajukan menurut cara ialah pertanyaan menggali. Pertanyaan-pertanyaan tersebut, lebih sering diajukan oleh guru dari pada siswa. pertanyaan sering muncul pada kegiatan pendahuluan dari pada kegiatan inti. Kemunculan-kemunculan pertanyaan tersebut belum berurutan sesuai dengan tingkatan ranah kognitif Taksonomi Anderson dan pertanyaan yang diajukan lebih pada macam pertanyaan menurut cara yakni pertanyaan menggali.
\end{abstract}

\section{Kata kunci: pertanyaan, macam-macam pertanyaan, taksonomi Anderson}

\begin{abstract}
This study aims to describe the levels and kinds of questions posed by teachers and students in the learning process of Indonesian Language classes VII-1, VII-3, and VII-4 of SMP Bengkulu 4 in the academic year 2017/2018. The method in this study is a qualitative descriptive method through observation and documentation (record and record). The results of the analysis of the emergence of questions submitted by the teacher in class VII-1, VII-3, and VII-4 in 8 meetings as many as 62 questions, then the questions often appear at the C-2 level (understanding) and the types of questions that are applied in a way are digging question. While the questions posed by students are as many as 7 questions, then the questions often appear at the C-2 level (understanding) and the types of questions that are asked according to the method are questions digging. These questions are more often asked by the teacher than the questions that are asked by the students and questions often arise in the preliminary activities rather than the core activities. The emergence of these questions has not been sequentially in accordance with the level of the cognitive domain of Anderson Taxonomy and the
\end{abstract}


questions asked are more on the types of questions according to the method of digging.

\section{Keywords: question, kinds of qeustions, Anderson taksonomy}

\section{PENDAHULUAN}

Pertanyaan bagian dari salah satu aspek keterampilan dalam proses belajar mengajar. Peran pertanyaan sangat penting dalam menyusun sebuah pengalaman belajar bagi siswa. Socrates meyakini bahwa semua ilmu pengetahuan akan diketahui atau tidak diketahui oleh siswa, hanya jika guru dapat mendemonstrasikan keterampilan bertanya yang baik dalam praktik pembelajaran di kelas (Helmiati, 2013: 57). Oleh sebab itu, setiap diri siswa harus ditanamkan jiwa bertanya.

Keterampilan bertanya sangat berguna untuk dimiliki setiap individu. Bertanya merupakan salah satu kegiatan yang digunakan setiap hari. Guru yang baik akan menanamkan ilmunya kepada siswa agar pandai dalam berinteraksi, salah satunya dengan bertanya. Bertanya juga akan membangkitkan minat, mengembangkan pola berpikir, cara belajar aktif dan rasa ingin tahu siswa terhadap sesuatu masalah yang sedang dibicarakan (Supriyadi, 2011: 108-159).

Bertanya merupakan salah satu ucapan verbal yang meminta respon dari seseorang yang dikenal, respon yang diberikan dapat berupa pengetahuan sampai dengan hal-hal seperti stimulasi efektif yang mendorong kemampuan berpikir (Asril, 2013: 81). Dalam proses belajar mengajar pola interaksi pertanyaan yang diajukan terjadi antara guru dengan siswa dan antara siswa dengan guru. Pertanyaan yang diajukan oleh guru biasanya dilakukan pada awal, kegiatan inti, dan kegiatan akhir pembelajaran.

Pertanyaan yang sering diajukan masih pada tingkat sederhana yaitu tingkat ingatan (C-1) dan pemahaman (C-2). Sedangkan, jenis pertanyaan lainnya akan menambah wawasan dan cara berpikir aktif. Pertanyaan yang diberikan pada tingkat pengetahuan/ingatan, belum sesuai untuk jenjang materi yang lebih tinggi. Sedangkan jenis pertanyaan tidak hanya dalam tingkat pengetahuan namun diteruskan dengan pertanyaan tingkat pemahaman, menerapkan, menganalisis, mengevalusi, dan berkreasi. Pembelajaran tersebut akan mengakibatkan siswa terdiam untuk meluangkan pertanyaan yang baru, dan siswa akan bertanya dengan cara yang sama, sehingga pembelajaran menjadi pasif.

Kualitas kegiatan proses pembelajaran ditentukan oleh kemampuan guru dalam pemanfaatan pertanyaanpertanyaan sebagai salah satu strategi untuk mencapai tujuan pembelajaran. Pertanyaan yang diajukan dapat dilihat dari maksudnya yang terdiri atas pertanyaan permintaan, pertanyaan retoris, pertanyan mengarahkan atau menuntun, dan pertanyaan menggali. Selain itu, juga terdapat pertanyaan dilihat dari tingkat kesulitan jawaban yang diharapkan bisa terdiri atas pertanyaan tingkat rendah dan pertanyaan tingkat tinggi, seperti pertanyaan pengetahuan, pertanyaan pemahaman, pertanyaan aplikatif, pertanyaan analisis, pertanyaan sintesis, dan pertanyaan evaluasi (Sanjaya, 2005: 158-160).

Ciri pertanyaan yang baik adalah pertanyaan yang memiliki kalimat singkat dan jelas. Tujuannya jelas, tidak terlalu umum dan luas. Setiap pertanyaan hanya untuk satu masalah. Mendorong anak 
untuk berpikir (kecuali kalau tujuannya sekedar melatih mengingat-ingat fakta). Jawaban yang diharapkan bukan sekedar "ya" atau "tidak". Bahasa dalam pertanyaan dikenal baik oleh siswa. Tidak menimbulkan tafsir ganda. Adanya ciri pertanyaan dengan baik akan memudahkan guru dan siswa dalam mengajukan pertanyaan (Sardiman, 2010: 214-215).

Macam-macam pertanyaan yang diajukan dapat dilihat dari pertanyaan menurut tujuan, pertanyaan menurut sifatnya, dan pertanyaan menurut caranya. Pertanyaan menurut tujuan di dalamnya terdapat pertanyaan kognitif, pertanyaan performansi, pertanyaan konsekuensi, dan pertanyaan eksplorasi. Pertanyaan menurut sifatnya dalamnya terdapat pertanyaan ingatan, pemahaman, penerapan, analisis, sintesis, dan evaluasi. Sedangkan, pertanyaan menurut cara di dalamnya terdapat pertanyaan mengarahkan, menggali dan memancing yang memiliki karakteristik masing-masing.

Proses pembelajaran Bahasa Indonesia harus ada standar pertanyaan yang diberikan agar lebih fokus pada materi pembelajaran. Tujuan pembelajaran Taksonomi Anderson memberikan fokus tingkatan pertanyaan khususnya dalam ranah kognitif. Dalam ranah kognitif, tingkatan pertanyaan dapat berupa mengingatan, memahami, menerapkan, menganalisis, mengevaluasi, sampai dengan berkreasi. Dengan kata lain, untuk mengakses pembelajaran siswa dalam kategori proses kognitif yang paling sederhana ini, yakni guru memberikan pertanyaan (Anderson dkk, 2017:99).

Timbulnya pertanyaan siswa yang baik dalam proses pembelajaran akan bergantung pada pertanyaan guru, sehingga guru harus memiliki kemampuan teknik bertanya yang baik. Apabila teknik bertanya guru terencana dengan baik, maka pertanyaan yang diajukan dapat membawa siswa pada pengalaman belajar yang diinginkan dan siswa dapat mengajukan pertanyaan yang sesuai dengan tujuan pembelajaran. Pertanyaan yang diajukan oleh guru dalam proses pembelajaran, di samping dapat meningkatkan kualitas pembelajaran, juga dapat digunakan untuk mengetahui ketepatan pemilihan pendekatan, metode dan teknik pembelajaran di dalam kelas, serta ketepatan materi yang diajarkan dengan situasi, kondisi, tujuan pembelajaran, dan kebutuhan siswa.

Artikel ini membicarakan tentang pertanyaan yang diajukan secara lisan oleh guru dan siswa dalam proses pembelajaran di kelas VII SMP Negeri 4 Kota Bengkulu.

\section{METODE}

Metode pada peneitian ini yakni, metode deskriptif kualitatif. Penelitian kualitatif mengungkapkan permasalahan yang belum jelas, holistik, komplek, dinamis dan juga bermaksud memahami situasi sosial mendalam, menemukan pola, hipotesis dan teori (Sugiono, 2006:399). Data pada penelitian ini berupa ujuaran guru dan siswa dalam mengajukan pertanyaan. Teknik pengumpulan data penelitian ini melalui 2 tahapan, yakni observasi dan dokumentasi (foto, rekam, dan catat). Teknik pengumpulan data dengan cara observasi dilakukan peneliti untuk mengetahui pertanyaan yang diajukan oleh guru dan siswa dalam proses pembelajaran Bahasa Indonesia. teknik pengumpulan data dengan cara dokumentasi dilakukan peneliti untuk memperlihatkan kejadian dalm proses pembelajaran Bahasa Indonesia dapat berupa foto, rekam, dan catat yang kemudian dituangkan dalam transkrip proses pembelajaran Bahasa Indonesia.

Penelitian ini dilaksanakan di SMP Negeri 4 Kota Bengkulu yang beralamatkan Jalan Cimanuk Km 6,5. Awal penelitian ini dilakukan pada tanggal 16 April dan berakhir pada tanggal 26 Mei 2018. Peneliti 
melakukan penelitan di kelas VII-1 s.d. VII4. Ibu Erni Hartati, S.Pd. merupakan salah satu guru Bahasa Indonesia di SMP tersebut. Beliau mengajar mata pelajaran bahasa Indonesia di kelas VII-1 s.d. VII-4. Data penelitian ini, adalah pertanyaan lisan yang diajukan guru dan siswa dalam proses pembelajaran Bahasa Indonesia. Penelitian ini tepatnya dilaksanakan pada semester II tahun ajaran 2017/2018.

\section{HASIL PENELITIAN DAN PEMBAHASAN Hasil Penelitian}

Berikut dipaparkan mengenai hasil dan penelitian:

\section{a. Identitas Pembelajaran}

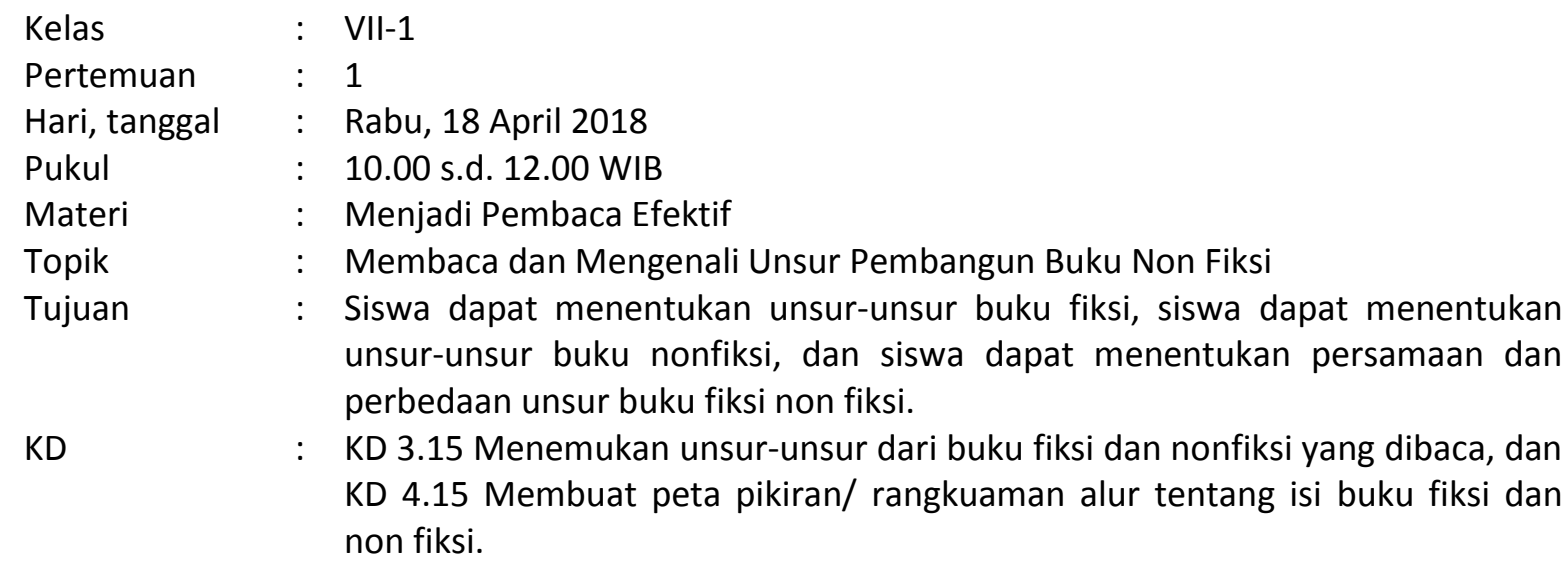
KD 4.15 Membuat peta pikiran/ rangkuaman alur tentang isi buku fiksi dan non fiksi.

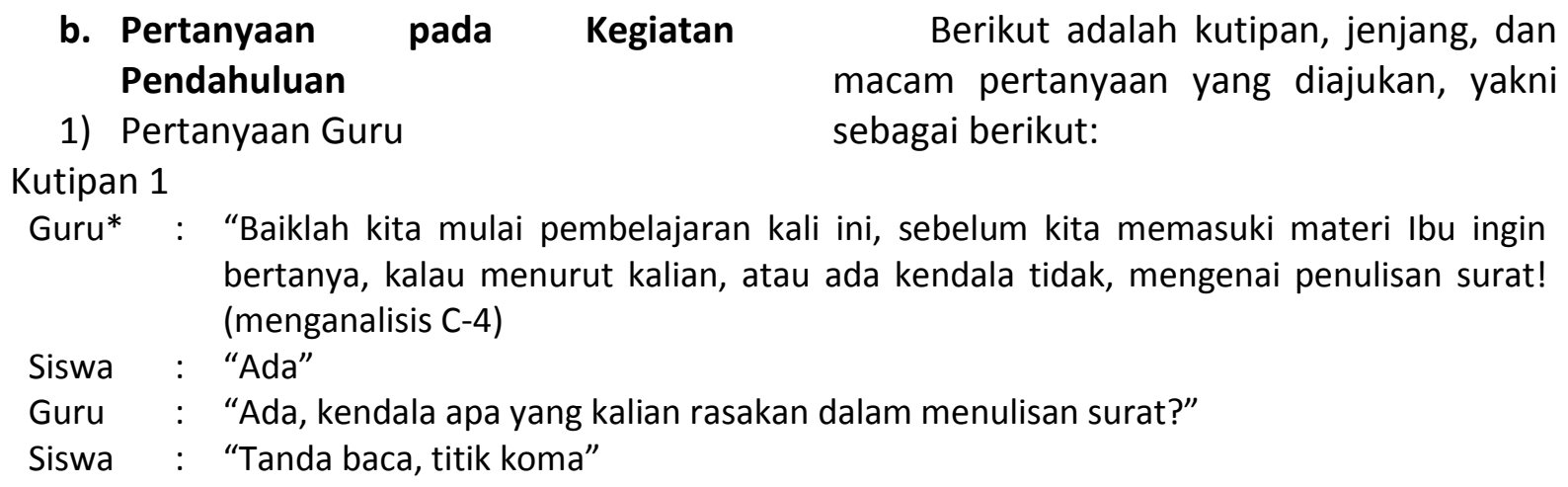

Kutipan di atas pada tanda * merupakan pertanyaan menggali dengan jenjang menganalisis (C-4). Maksud pertayaan menggali yakni guru memberikan pertanyaan lanjutan yang akan mendorong murid untuk lebih mendalami gagasan pokok. Kemudian pertanyaan guru pada jenjang menganalisis C-4 dengan kategori mengorganisasi dengan membuat garis besar yang akan dituangkan kembali mengenai materi sebelumnya jika ada yang belum paham.
Kemudian kutipan pada tanda * bukan merupakan pertanyaan yang baik karena jawaban yang diingikan bukan sekedar ada/tidak. Pertanyaan yang baik adalah pertanyaan yang memberikan siswa pengetahuan yang baru.

\section{2) Pertanyaan siswa}

Berikut adalah kutipan, jenjang, dan macam pertanyaan yang diajukan, yakni sebagai berikut: 


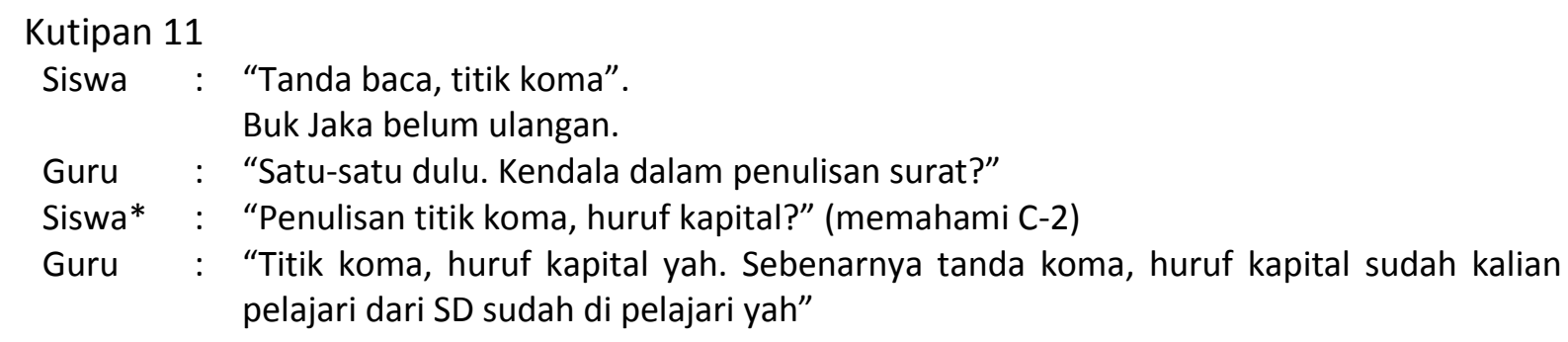

Kutipan di atas pada tanda * berkaitan dengan materi pembelajaran, merupakan pertanyaan pemahaman yakni buku yang berhubungan dengan dengan jenjang memahami (C-2). buku fiksi atau buku nonfiksi. Bagi siswa Pertanyaan siswa, menginginkan yang tidak membawa buku fiksi atau pengetahuan yang lebih lagi kerena siswa nonfiksi diperintahkan untuk mencari buku telah melakukan namun siswa masih di perpustakaan sekolah dan semua siswa merasa kebingungan. Pertanyaan yang membaca buku di sana sehingga, siswa diajukan oleh siswa adalah jenjang terfokus untuk membaca buku dan tidak memahami (C-2), karena guru dan siswa terdapat pertanyaan dari siswa maupun lainnya menjawab pertanyaan dengan informasi pemahaman yang mereka dapat.

\section{c. Pertanyaaan pada Kegiatan Inti}

Saat pembelajaran di kegiatan inti, guru menyuruh siswa untuk melakukan kegiatan membaca buku. Siswa diperintah oleh guru untuk membaca buku yang Kutipan 12

Guru* : "Tadi, kalian sudah membaca ada yang perlu ditanyakan mengenai kegiatan yang kalian lakukan tadi, kegiatan membaca tadi ada yang perlu ditanyakan!" (menganalisis C-4)

Siswa : "Tidak"

Kutipan di atas pada tanda * merupakan pertanyaan menggali dengan jenjang mengevaluasi (C-5). Maksud pertaNyaan menggali yakni guru memberikan pertanyaan lanjutan yang akan mendorong murid untuk lebih mendalami gagasan pokok. Kemudian pertanyaan guru pada jenjang menganalisis C-4 dengan kategori mengorganisasi dengan membuat garis besar yang akan dituangkan kembali mengenai materi sebelumnya jika ada yang belum paham.

Kemudian kutipan pada tanda * bukan merupakan pertanyaan yang baik karena jawaban yang diinginkan bukan sekedar ada/tidak. Pertanyaan yang baik adalah pertanyaan yang memberikan siswa pengetahuan yang baru.

2) Pertanyaan Siswa

Berikut adalah kutipan, jenjang, dan macam pertanyaan yang diajukan, yakni sebagai berikut: 


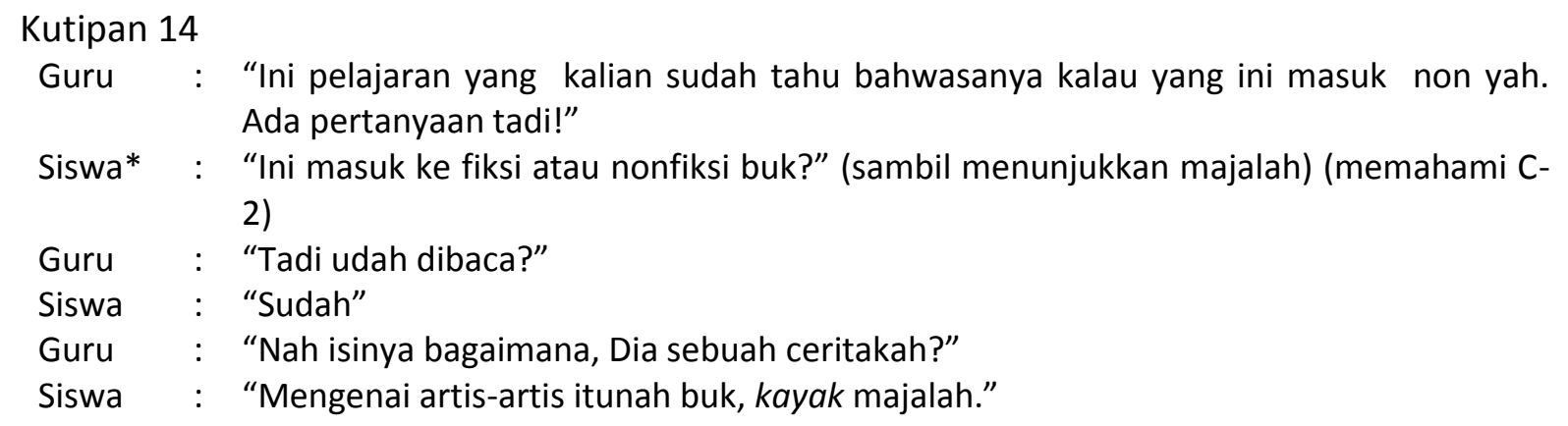

Kutipan di atas pada tanda * merupakan pertanyaan menggali dengan jenjang memahami (C-2). Petanyaan yang diajukan oleh siswa merupakan pertanyan menggali karena siswa ingin mengetahui kembali contoh buku/ majalah yang dibawa termasuk fiksi atau nonfiksi. Jenjang pertanyaan yang diajukan oleh siswa adalah jenjang pertanyaan C-2, karena pertanyaan tersebut termasuk dalam kategori mengklasifikasikan contoh buku/ majalah tersebut masuk dalam fiksi atau nonfiksi.

\section{Pembahasan}

Berikut dipaparkan mengenai pembahasan pada penelitian ini, yakni:

\section{a. Pertanyaan Guru}

1) Taksonomi Anderson

Analisis dan jumlah kemunculan pertanyaan yang diajukan oleh guru pada kelas VII-1, VII-3 dan VII-4 sebanyak enam puluh pertanyaa lisan. Enam puluh dua pertanyaan lisan yang diajukan oleh guru tersebut terdiri dari dua puluh pertanyaan dalam dua kali pertemuan di kelas VII-1, dua puluh dua pertanyaan dalam empat kali pertemuan di kelas VII-3, dan dua puluh pertanyaan dalam dua kali pertemuan di kelas VII-4.

Semua jumlah jenjang pertanyaan yang diajukan oleh guru dalam delapan kali pertemuan. Dimulai dari C-1 berjumlah empat belas jenjang, C-2 berjumlah empat puluh jenjang, C-3 berjumlah satu jenjang, C-4 berjumlah empat jenjang, C-5 berjumlah 3 jenjang, dan C- 6 berjumlah nol jenjang. Jumlah jenjang pertayaan yang sering diajukan oleh guru ialah jenjang C-2 (memahami).

\section{2) Macam-Macam Pertanyaan}

Macam pertanyaan yang sering dilakukan oleh guru yakni, macam pertanyaan menurut cara. Pertanyaan menurut cara di dalamnya terdapat pertanyaan memancing, pertanyaan menggali, dan pertanyaan mengarahkan. Guru seringkali memberikan pertanyaan yang menggali pada siswa. hal ini disebabkan oleh pengetahuan siswa yang kurang memadai mengenai materi yang diajarkan, sehingga guru sering memberikan pertanyaan yang menggali. Adanya pertanyaan yang menggali memberikan siswa pengetahuan yang lebih dan mendalam, yang kemudiannya siswa dapat menguasi materi yang diajarkan dan dapat menuangkan dalam kehidupan sehari-hari dan menjadikannya bermanfaat.

\section{b. Pertanyaan Siswa}

1) Taksoonomi Anderson

Kemunculan pertanyaan yang diajuka oleh siswa pada kelas VII-1, VII-3 dan VII-4 sebanyak tujuh pertanyaa lisan. tujuh pertanyaan lisan yang diajukan oleh siswa tersebut terdiri dari empat pertanyaan dalam dua kali pertemuan di kelas VII-1, satu pertanyaan dalam empat kali pertemuan di kelas VII-3, dan dua pertanyaan dalam dua kali pertemuan di kelas VII-4.

Semua jumlah jenjang pertanyaan yang diajukan oleh siswa dalam delapan 
kali pertemuan. Dimulai dari C-1 berjumlah nol jenjang, C-2 berjumlah lima jenjang, C3 berjumlah dua jenjang, C- 4 berjumlah nol jenjang, C- 5 berjumlah nol jenjang, dan C- 6 berjumlah nol jenjang. Jumlah jenjang pertayaan yang sering diajukan oleh siswa ialah jenjang C-2 (memahami).

\section{2) Macam-Macam Pertanyaan}

Macam pertanyaan yang sering diajukan oleh siswa yakni, macam pertanyaan menurut cara. Pertanyaan menurut cara di dalamnya terdapat pertanyaan memancing, pertanyaan menggali, dan pertanyaan mengarahkan. Siswa lebih sering memberikan pertanyaan yang menggali untuk mengetahui materi yang mendalam. Hal ini, disebabkan oleh siswa yang masih merasa kebingungan terhadap materi yang diberikan. Adanya pertanyaan yang menggali memberikan siswa pengetahuan yang lebih dan mendalam lagi, yang kemudiannya siswa mampu menguasi materi yang diajarkan dan dapat menuangkan dalam kehidupan sehari-hari dan menjadikannya bermanfaat.

Berdasarkan pemaparan yang telah dibicarakan, kemunculan pertanyaanpertanyaan lebih sering diajukan oleh guru dari pada siswa. Kemunculan pertanyaan yang diajukan oleh guru tersebut sering terlihat pada kegiatan pendahuluan. Pertanyaan yang diajukan oleh guru pada kegiatan pendahuluan sebanyak 40 pertanyaan dalam 9 kali pertemuan. 40 pertanyaan yang sering muncul dalam kegiatan pendahulaun tersebut, terdiri dari 15 jenjang pertanyaan mengingat (C-1), 11 pertanyaan memahami (C-2), 7 jenjang pertanyaan menerapkan (C-3), 0 jenjang pertanyaan menganalisis (C4), 7 jenjang pertanyaan mengevaluasi (C-5), dan 0 jenjang pertanyaan berkreasi (C-6). Jadi, jenjang pertanyaan yang sering muncul dalam 9 kali pertemuan pada kegiatan pendahulan yang diajukan oleh guru adalah jenjang pertanyaan mengingat (C1).

\section{PENUTUP}

\section{Kesimpulan}

Berasarkan hasil penelitian dan pembahasan pada analisis pertanyaan guru dan siswa dapat disimpulkan sebagai berikut.

Pertanyaan yang diajukan oleh guru dalam proses pembelajaran Bahasa Indonesia sebanyak enam puluh enam pertanyaan dan pertanyaan yang diajukan lebih banyak pertanyaan pada jenjang memahami (C-2). Pertanyaan yang diajukan oleh siswa sebanyak tujuh pertanyaan yang mengarah pada pertanyaan memahami (C-2). Selanjutnya, macam-macam pertanyaan yang terdiri dari macam pertanyaan menurut tujuan, macam pertanyaan menurut sifat, dan macam pertanyaan menurut cara. Macammacam pertanyan yang sering diajukan oleh guru adalah pertanyaan menurut cara pada pertanyaan menggali. Kemudian macam pertanyaan yang sering diajukan oleh siswa yakni macam pertayaan menggali.

Jadi, dapat disimpulkan bahwa pertanyaan yang diajukan oleh guru lebih banyak dari pada pertanyaaan siswa. Pertanyan-pertanyaan yang diajukan masih pada tingkat LOTS (Lowder Order Thinking Skill), kemudian pertanyaan lebih sering muncul pada kegiatan pendahuluan daripada kegiatan inti. Dan, masih terdapat pertanyaan guru yang belum termasuk dalam ciri pertanyaan yang baik.

\section{Saran}

Hendaknya guru meningkatkan pemahaman mengenai teknik-teknik bertanya dalam proses pembelajaran supaya tidak mengacak runtutan pada ranah kognitif. Semakin tinggi tingkan siswa belajar semakin tinggi pula jenjang pertanyaan yang diajukan. Sehingga, siswa 
mampu memahami berpikir kritis dalam memahami materi pembelajaran dan tidak mengulang-ulang pertanyaan yang sama.

Peneliti berharap siswa aktif dalam mengajukan pertanyaan dan memperhatikan siswa lain yang sedang bertannya. Agar pertanyaan yang telah diajukan tidak ditanyakan kembali. Kemudian diharapkan siswa berusaha dan mampu meningkatkan pengetahuan dan kemampuan bertanya untuk meningkatkan kualitas pertanyaan. Mampu memahmai materi dengan baik agar dapat mengajukan pertanyaan-pertanyaan yang belum dipahami.

\section{DAFTAR PUSTAKA}

Anderson, dkk. 2017. Kerangka Landasan Untuk Pembelajaran, Pengajaran, dan Asesmen Revisi Taksonomi Bloom. Diterjemahkan oleh Agung
Prihantoro. Yogyakarta: Pustaka Belajar.

Asril, Zainal. 2013. Micro Teaching disertai dengan Pengalaman Lapangan. Jakarta: Raja Grafindo.

Helmiati. 2014. Micro Teaching Melatih Keterampilan Dasar Mengajar. Yogyakarta: Aswaja Presindo.

Sanjaya, Wina. 2005. Pembelajaran dalam Implementasi Kurikulum Berbasis Kompetensi. Jakarta: Prenada Media.

Sardiman, A. M. 2010. Interaksi dan Motivasi Belajar Mengajar. Jakarta: PT RajaGraFindo Persada.

Sugiyono. 2006. Metode Penelitian Pendidikan Pendekatan Kuantitatif, Kualitatif, dan $R$ \& $D$. Bandung: Alfabet.

Supriyadi. 2011. Strategi Belajar dan Mengajar. Yogyakarta: Cakrawala IImu. 